\title{
OSTEOINTEGRATION OF AN UNCEMENTED MODULAR REVISION STEM IMPLANTED DURING REVISION HIP SURGERY
}

\author{
Pavel Šponer ${ }^{1}$, Tomášš Kučera ${ }^{1}$, Karel Urban ${ }^{1}$, David Zittko ${ }^{1}$, Daniel Diaz-Garcia ${ }^{2}$, Michal Grinac $^{l}$
}

Charles University in Prague, Faculty of Medicine and University Hospital in Hradec Králové, Czech Republic: Department of Orthopaedic Surgery ${ }^{1}$, Department of Histology and Embryology ${ }^{2}$

\begin{abstract}
Summary: Background: Though mid-term survival rates of over 95\% in several series have been published, there is still a paucity of related literature regarding the role of vertical stem instability in the osteointegration of fluted tapered stems. This paper presents a comprehensive and prospective assessment on short-term experiences with uncemented modular femoral stem in the treatment of defective femur during revision surgery of total hip replacement. Materials and methods: Clinical and radiological monitoring of 20 consecutive patients with implanted tapered fluted revision stem (Lima Corporate, Udine, Italy) was of 27 months in average (20-35 months). The average pre-operative Merle d'Aubigné and Postel method score was 6.3 points (3-10 points). The frequency of femur defects, classified according to Paprosky, was IIIA $=9$ and IIIB $=11$. Results: During last follow-up, the Merle d'Aubigné and Postel hip score was on average 11.7 (6-16 points). Compared to post-operation radiograph, stem migration of $1.9 \mathrm{~mm}(0-11 \mathrm{~mm})$ on average was found. This vertical stem migration was observed only when comparing hip radiographs immediately after surgery, and at 6 weeks post-surgery. The Paprosky IIIA defects group, presented a subsided stem by an average of $1.5 \mathrm{~mm}$. In the group of Paprosky IIIB defects, the stem subsidence was on average $2.3 \mathrm{~mm}$. All 20 patients in the study showed excellent osteointegration of the uncemented revision modular stem. Conclusions: This study found and excellent osteointegration of the Lima uncemented tapered fluted revision modular stem in defective femur with a cortical bone segment present in the diaphyseal isthmus area. The initial vertical instability leading to stem migrating during the first six weeks following surgery did not, however, affect its osteointegration.
\end{abstract}

Key words: Total Hip Arthroplasty; Revision; Uncemented Femoral Stem; Instability; Osteointegration

\section{Introduction}

Without doubt, the implantation of a total hip replacement is one of the highly efficient surgical techniques leading to pain reduction, restoration of joint function and improvement in the patient's quality of life. With the growing number of primary total hip joint replacements, together with the treatment of younger and more active patients, a substantial surge in the number of revision operations is to be expected over the next few decades $(5,19)$.

The aim of revision surgery is to create a stable assembly, protect bone and soft tissues, augment bone deficits, restore the biomechanical function of the hip and to create the pre-conditions for any future operation. Femur reconstruction during a revision total hip replacement can be the most demanding phase of the operation. Femur bone defects may result from aseptic loosening, osteolysis, infection, periprosthetic fractures, stress shielding and implant extraction. A guide for selecting the appropriate method for femoral reconstruction during revision surgery is the classification system for femoral defects, of which several have been developed over the years $(20,22)$.

Use of cemented implants is indicated for smaller femoral defects, particularly in elderly patients. Besides the cement-in-cement technique, which calls for minimum bone defects, the impaction grafting method has been used for a long time. Long cemented femoral components are indicated in biologically old patients who are unable to relieve the limb during the post-operative period. It is generally true, however, that cemented implants are not as frequently used during revision operations of femoral component as uncemented implants, which differ in their degree of rotational and vertical stability. Uncemented revision monoblock stems are appropriate during revision surgery with smaller cavitary and segmentary defects. Modular uncemented revision stems differ in the manner 
by which they achieve vertical stability. The fit and fill principle is based on an exact preparation of the bonebed in the defective proximal femur and subsequent exact implantation of the proximal module (25). If the proximal femur is not able to bear the vertical load, a modular tapered fluted stem is indicated. Reconstruction of large segmentary defects of the proximal femur is possible using a solid allograft (applied as an onlay graft or as composite formed by an allograft of the entire proximal femur and a revision modular stem) or morselized allografts impacted into the defective proximal femur ensuring their shape and cohesion with a titanium mesh (20).

Although mid-term survival rates of $>95 \%$ in several series have been published, there is still a paucity of related literature regarding the role of vertical stem instability in the osteointegration of fluted tapered stems $(23,28,31)$. A comprehensive and prospective assessment of short-term experience with a Lima revision modular tapered stem in the treatment of defective femur during revision surgery of total hip replacement is presented in this paper.

\section{Materials and Methods}

\section{Patients}

The retrospective study was performed in accordance with the ethical standards stipulated in the 1964 Declaration of Helsinki as revised in 2000. An informed consent form concerning the operative technique to be performed was signed by all patients. Patient rights are protected by our institutional rules requiring patients to be informed at the time of examination about the possibility that their medical records and radiographs will be reviewed for scientific purposes. The retrospective study is comprised of 20 consecutive patients that underwent surgery between September 2010 and January 2012 to implant a Lima revision modular stem (Lima Corporate, Udine, Italy). The basic data concerning the group's assessment are given in Table 1 . The type of stem used during primary implantation, reason of stem revision, the contemporary surgery in the area of the acetabulum and the manner of stem extraction during the revision surgery are given in Table 2 .

Tab. 1: Basic description of the group of patients.

\begin{tabular}{|l|c|c|}
\hline Parameter & Description & Value (for n= 20) \\
\hline Sex & Female & 10 \\
\hline & Male & $66(55-71)$ \\
\hline Age at time of revision(years) & & $27.2(20.5-32.3)$ \\
\hline BMI & & $1.68(1.47-1.83)$ \\
\hline Height $(\mathrm{m})$ & & $77.3(58.0-98.0)$ \\
\hline Weight $(\mathrm{kg})$ & Primary osteoarthritis & 6 \\
\hline Diagnosis for primary implantation & Post-dysplastic osteoarthritis & 9 \\
\hline & Fracture of femoral neck & 3 \\
\hline & Avascular necrosis of femoral head & 1 \\
\hline & M Bechterew & 1 \\
\hline Aatient type according to modified Charnley classification & A $^{+}$ & 2 \\
\hline & B1 & 9 \\
\hline
\end{tabular}

${ }^{+}$A (hip disability on one side treated with total endoprosthesis, contralateral hip is without clinical and radiological signs of damage)

* B1 (both hips treated by endoprosthesis)

** B2 (assessed joint is treated by endoprosthesis, contralateral hip joint is treated for arthrosis)

${ }^{\times} \mathrm{C}$ (multiple joint disability limiting patient's mobility)

Tab. 2: Basic characteristics of revision operations.

\begin{tabular}{|l|c|}
\hline Originally stem used & 19 \\
\hline cemented & 1 \\
\hline uncemented & 6 \\
\hline Reason for revision & \\
\hline aseptic loosening of both components &
\end{tabular}

\begin{tabular}{|l|c|}
\hline aseptic loosening of stem & 4 \\
\hline $\begin{array}{l}\text { aseptic loosening of stem with positive intraoperative } \\
\text { cultivation }\end{array}$ & 1 \\
\hline $\begin{array}{l}\text { septic loosening with extraction of both components } \\
\text { and spacer }\end{array}$ & 2 \\
\hline
\end{tabular}




\begin{tabular}{|l|c|}
\hline periprosthetic fracture & 4 \\
\hline broken stem & 1 \\
\hline broken stem and periprosthetic fracture & 1 \\
\hline stem malposition & 1 \\
\hline Current solution on the acetabulum side & 3 \\
\hline morselized allografts, uncemented socket & 3 \\
\hline autografts, uncemented socket & 1 \\
\hline uncemented socket & 1 \\
\hline morselized allografts, augmentation, cemented socket & 5 \\
\hline insert exchange due to wear & \\
\hline Extraction of femoral components & 10 \\
\hline trepanation window & 3 \\
\hline trepanation window during previous stem extraction & 3 \\
\hline $\begin{array}{l}\text { transfemorally during treatment of periprosthetic } \\
\text { fracture }\end{array}$ & 2 \\
\hline transfemoral approach & 2 \\
\hline antegrade from proximal end of femur & \\
\hline
\end{tabular}

All surgical procedures were performed in an aseptic operating theatre, using a Bauer approach. Antibiotic prophylaxis lasted 24 hours, except for 2 patients after previous extraction of both components and the implantation of a spacer for septic loosening, and 1 patient with a positive intraoperative cultivation taken during the revision for assumed aseptic stem loosening. These three patients were provided with targeted antibiotic therapy for 8 weeks. Low-molecular-weight heparin was used to prevent thromboembolic disease. Post-operative physiotherapy started the first post-op day, full weight-bearing was allowed after 12 to 24 weeks.

The average pre-operative Merle d'Aubigné and Postel method score was 6.3 points (3-10 points). The frequency of femur defects classified according to Paprosky was IIIA= 9 and IIIB $=11$. The average follow-up period was of 27 months (20-35 months).

\section{Description of the implant}

The Lima modular tapered fluted revision stem, made of titanium alloy Ti6Al4V, has a straight distal anchoring module of conical shape (with a $1{ }^{\circ} 50^{\prime}$ angle), its dimensions are of 140 or $200 \mathrm{~mm}$ long and 14-24 mm in diameter ( $2 \mathrm{~mm}$ increments), with 8 longitudinally-oriented anchoring blades. After positioning and pushing onto the Morse taper (which is deflected by $4^{\circ}$ from the long axis of the distal module's anchoring part) the proximal module is locked to the distal module with a locking screw. The proximal module is available in 7 sizes $(50-110 \mathrm{~mm}$ long with $10 \mathrm{~mm}$ increments), with a neck-shaft angle of $131^{\circ}$ (40 mm offset) and $135^{\circ}$ (35 mm offset) and a 12/14 neck cone. Primary stem stability is achieved by press-fitting into the distal femur after preparing the corresponding bone bed. While vertical stability is based on the tapered shape of the distal module, rotary stability is ensured by the longitudinal blades. Secondary stem stability (osteointegration) is made possible by mechanical surface manufacturing of the stem and the proximal module by a jet of corundum particles which roughens the contact surface.

A Lima metallic head with a diameter of 28,32 or $36 \mathrm{~mm}$ with neck lengths of S, M, L, XL size were used for all patients.

\section{Clinical examination}

The patients were clinically examined before surgery and at different points after surgery: 6 weeks, $3,6,12,24$, and 36 months. The data needed to calculate the Merle d'Aubigné and Postel score as modified by Charnley was acquired in the last follow-up examination (7). The patient gave a subjective view on the state of the operated hip joint, followed by a clinical physical examination (palpation, range of movement, evaluation of gait pattern).

\section{Radiological examination}

The radiological examination compared radiographs of the hip in the anteroposterior view the following day after surgery, then at 6 weeks and 3 months and during the last follow up.

Stem position was assessed in relation to the long axis of the femur, whilst a deviation of up to $5^{\circ}$ was considered neutral implantation. The degree of stem migration was determined from the distance between the top edge of the stem's body and the apex of the greater trochanter on the post-operational and subsequent radiographs. In addition a qualitative assessment of the bone-bed surrounding the stem was carried out. The continuous soft edging around the stem not exceeding $2 \mathrm{~mm}$ was interpreted as a radiolucent line. A localised area of bone resorption with a width greater than $2 \mathrm{~mm}$ was determined to be osteolysis. Reactions such as stress shielding and bone bridge formation under the stem tip were also assessed. The Gruen (13) method was used for localisation of the affected zones. Heterotopic ossifications were evaluated according to Brooker (6).

\section{Results}

\section{Clinical results}

During the last follow-up, the Merle d'Aubigné and Postel hip score as modified by Charnley was on an average of 11.7 (6-16 points), which is an improvement on the pre-operative state of 5.4 points. 12 patients $(60 \%)$ did not have pain in the hip area. Nine patients $(45 \%)$ stated that they did not use any aid when walking or, at most, used a walking stick when walking a long distance. On the other hand, 8 patients $(40 \%)$ walked with the support of forearm crutches. There was no patient in the group unable to walk. 


\section{Radiological results}

The position of the stem was neutral for all 20 patients. Compared to the post-operation radiograph, a stem migration of $1.9 \mathrm{~mm}(0-11 \mathrm{~mm})$ on average was found; this vertical stem migration was observed only when comparing hip radiographs immediately after surgery and at 6 weeks. In the group of Paprosky IIIA defects (9 patients), the stem subsided by an average of $1.5 \mathrm{~mm}$ whilst no vertical stem

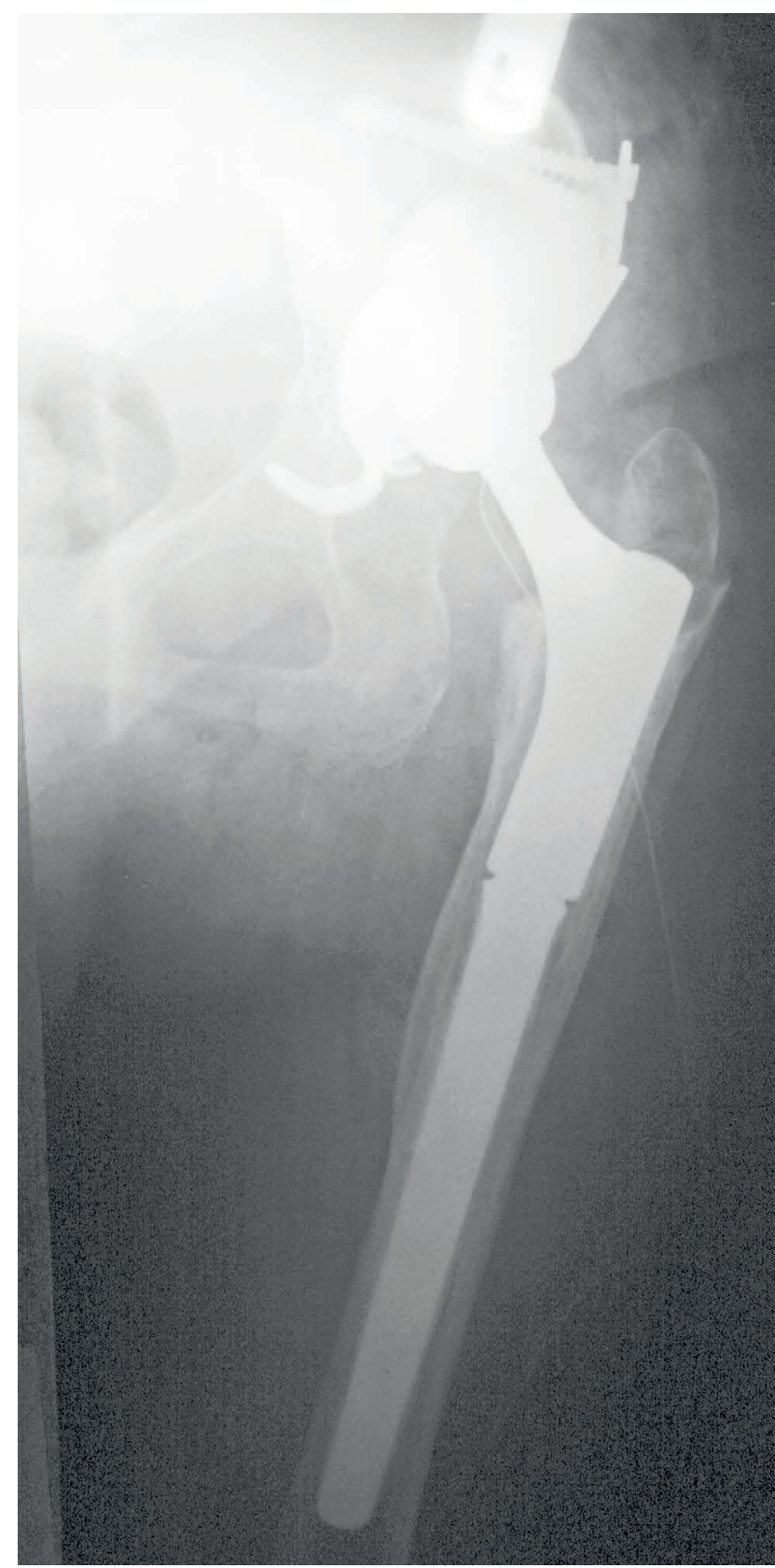

Fig. 1a: Uncemented modular tapered fluted revision stem on anteroposterior view one day after surgery. The top edge of the stem's body is bellow the level of the apex of the greater trochanter. migration was observed in 6 patients (Fig. 1a,b,c). In the group of Paprosky IIIB femur defects (11 patients), stem subsidence was of $2.3 \mathrm{~mm}$ on average whilst no vertical stem subsidence was observed in 7 patients.

Stem osteointegration was present in all 20 patients although changes were registered during a qualitative evaluation of the bone bed surrounding the stem in 16 patients. Table 3 shows the character and localisation of these changes. A bone bridge formation below the stem apex was found in 3 patients.

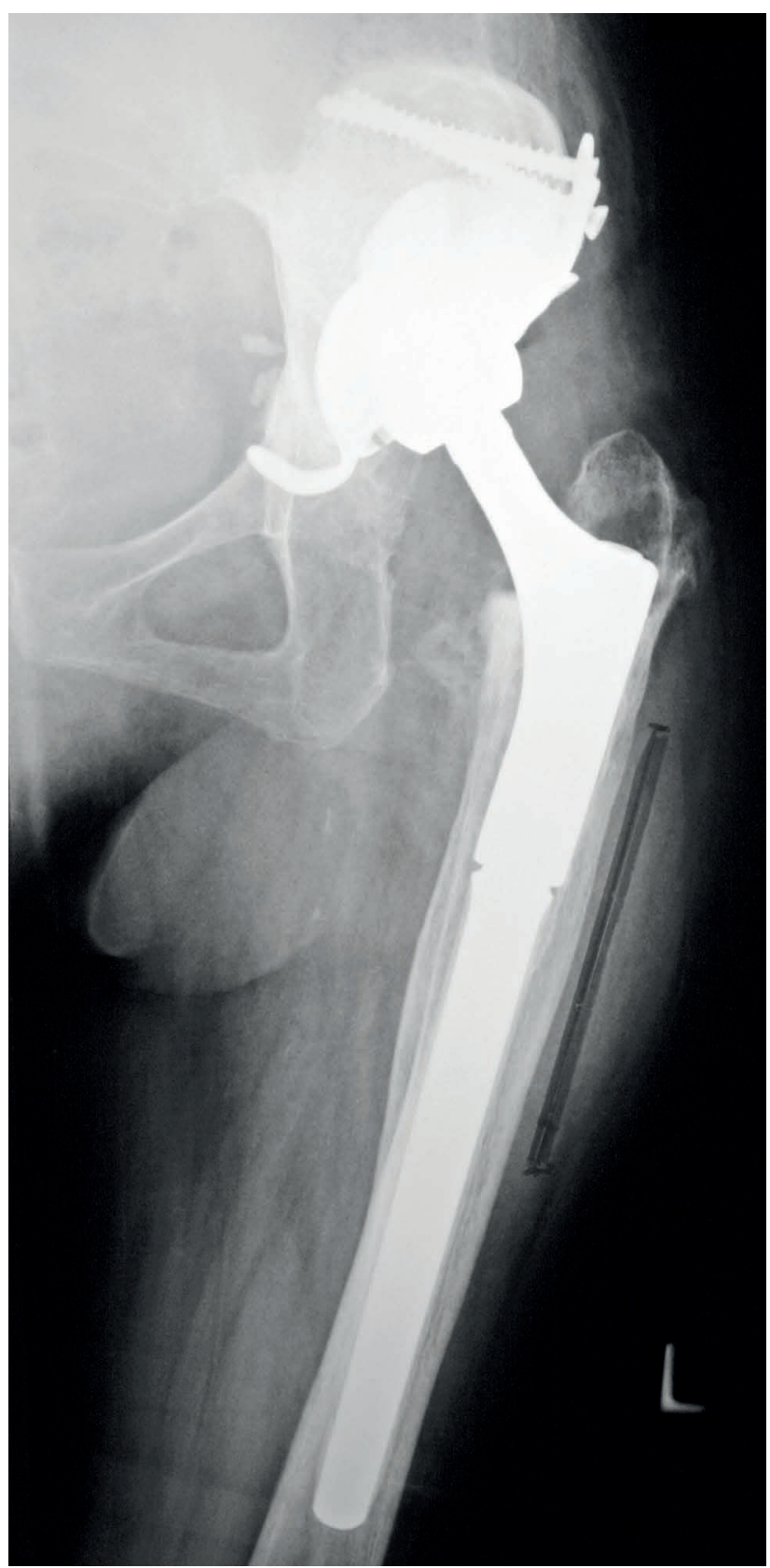

Fig. 1b: The top edge of the stem's body is uncharged below the level of the apex of the greater trochanter on anteroposterior view 6 weeks after surgery. 


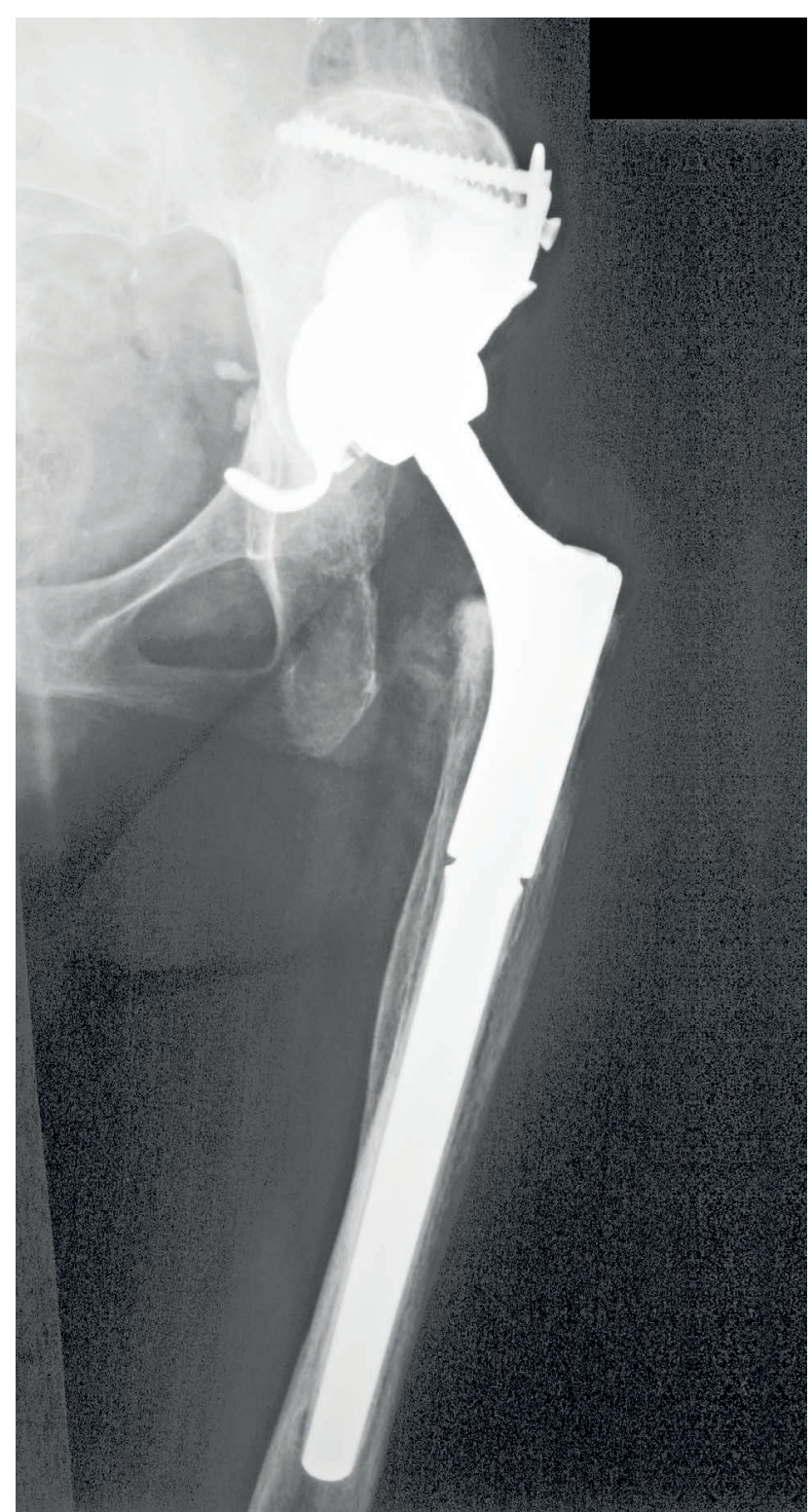

Fig 1c: Uncemented modular tapered fluted revision stem is well osteointegrated on anteroposterior view 3 months after surgery.

Tab. 3: Bone bed's qualitative radiological evaluation around the implanted stem.

\begin{tabular}{|l|c|c|}
\hline Localisation & Character & Number of patients \\
\hline Gruen zone 1 & radiolucent line & 2 \\
\cline { 2 - 3 } & osteolysis & 6 \\
\hline \multirow{2}{*}{ Gruen zone 2 } & radiolucent line & 1 \\
\cline { 2 - 3 } & osteolysis & 4 \\
\hline Gruen zone 3 & radiolucent line & 1 \\
\cline { 2 - 3 } & osteolysis & 2 \\
\hline Gruen zone 6 & osteolysis & 4 \\
\hline Gruen zone 7 & osteolysis & 7 \\
\hline
\end{tabular}

\section{Complications}

In our patient group, one haematoma was observed in the surgical wound which was treated by early revision, and one serous secretion from the surgical wound treated with conservative therapy. In both cases the wound healed without affecting the implant's function. One patient had post-surgical peroneal nerve palsy, which did not respond to conservative treatment. Heterotopic ossification (I to III degree according to Brooker) developed in 9 patients.

\section{Discussion}

When choosing the appropriate femoral reconstruction method during hip revision surgery, the presence of bone defects plays a vital role. It is important to distinguish the two basic types during their classification: segmental and cavitary. For a segmental defect, bone loss in the supporting cortical bone of the femur is typical while in a cavitary defect the wall is retained, though this may be thinned to the extent of a very thin cortical shell.

Of the various classification systems, good experience has been gained with the classification of femoral defects as defined by Paprosky, which is based on the assessment of bone loss degree and on the localisation/amount of remaining bone available for femoral reconstruction using an uncemented component, which is the implant preferred by the author during revision operations (8) (Table 4).

Tab. 4: Paprosky's classification of femoral defects.

\begin{tabular}{|l|l|}
\hline $\begin{array}{l}\text { Type of } \\
\text { defect }\end{array}$ & Characteristics \\
\hline I & $\begin{array}{l}\text { Minimum loss of metaphyseal cancellous bone with } \\
\text { intact diaphysis }\end{array}$ \\
\hline II & $\begin{array}{l}\text { Extensive loss of metaphyseal cancellous bone with } \\
\text { intact diaphysis }\end{array}$ \\
\hline IIIA & $\begin{array}{l}\text { Metaphysis is severely damaged thus is not support- } \\
\text { ive, more than 4 cm long segment of intact cortical } \\
\text { bone is present in the area of the femoral isthmus of } \\
\text { the diaphysis allowing distal fixation }\end{array}$ \\
\hline IIIB & $\begin{array}{l}\text { Metaphysis is severely damaged, less than } 4 \text { cm } \\
\text { long segment of intact cortical bone is present in the } \\
\text { area of the femoral isthmus of the diaphysis }\end{array}$ \\
\hline IV & $\begin{array}{l}\text { Extensive metaphyseal damage with open femoral } \\
\text { canal, in the diaphyseal region femoral isthmus does } \\
\text { not allow support }\end{array}$ \\
\hline
\end{tabular}

For a type I femoral defect, only a minimal loss of metaphyseal cancellous bone with an intact diaphysis is detected during revision surgery and thus a cemented or uncemented implant can be used. For a type II defect, extensive loss of the metaphyseal cancellous bone with an intact diaphysis is detected during a revision operation and stem fixation using bone cement is not reliable (9). In this indication, the 
successful use of uncemented stems has been published, both distally fixed and, with regards to the well-preserved metaphyseal support, implants primarily fixed onto the metaphysis $(8,15)$. Excellent results have been published using a modular, uncemented, tapered stem with longitudinal blades providing excellent initial rotational and axial stability during severe damage of the metaphysis, even with a very short femoral isthmus (4). A potential problem accompanying use of this implant is stem subsidence (8), however, the modularity of many distally anchored stem systems has brought an increase in stability by distal anchorage of the femoral component, as the actual situation requires, and then completing the proximal part of the femoral component to restore the necessary length of the limb and stability of the revision arthroplasty. Nevertheless, for a type IIIB some authors suggest the use of femoral components where diaphyseal locking is possible (20). For a type IV femoral defect, extensive metaphyseal and diaphyseal damage is typical with an enlarged femoral canal, while the femoral isthmus does not allow support. Use of an uncemented implant in such cases is not appropriate as it is difficult to ensure enough initial implant stability for osteointegration. If the cortical bone bed of the proximal part of the femur is intact, reconstruction is possible using impaction grafting $(10,12,30)$. This technique is, however, not only technically demanding and time-consuming, but also expensive due to the number of bone grafts. Even though impaction grafting is associated with implant subsidence and periprosthetic fracture (both perioperative and post-operative), it can be an excellent solution for difficult femoral revision where it is not possible to use uncemented replacements $(17,27)$. The alternative, when attempting to restore bone stock in young patients, is to use a composite of allografts and hip revision stem whilst in older patients it is possible to use hip prosthesis replacing the proximal part of the femur $(3,21)$. In some cases, a megaprosthesis replacing the entire femur is indicated (20).

The favourable results obtained from the use of an uncemented revision modular stem are comparable with the work of other authors $(14,26)$. In the discussion framework, concerning primary and secondary implant stability, it has been argued in the literature that secondary osteointegration and therefore long-term stability are possible, lacking noticeable post-operative migration of the stable implant (24). Despite firm intraoperative anchorage of the stem's distal module with a very short femoral isthmus, its subsidence cannot be ruled out. Regardless, the observed vertical stem instability leading to initial vertical migration during the first six weeks following surgery did not affect implant osteointegration. Similar findings were recently observed by other authors (1, $18,29)$. An orthostatic collapse with a fall during physiotherapy led to the largest $(11 \mathrm{~mm})$ vertical stem subsidence in a patient after a prior transfemoral approach although in this case, failure of osteosynthesis or a periprosthetic fracture was not radiologically proven.

The femur's bone bed quality is an important factor during stem reimplantation. In practice, during a revision operation the problem lies within the quality of autologous grafts for the higher age group of patients; further, there is the issue regarding the collection of a sufficient quantity of these grafts thereby extending operating time and thus increasing surgical trauma. Generally, a solid allograft can be used to restore bone stock in the femur applied either in the form of an onlay graft or by replacing the entire proximal femur with a solid allograft. Another possible solution are morselized allografts impacted into the defect, using a titanium mesh to secure the missing wall. To improve the allografts' biological and mechanical properties, osteoinductive growth factors and synthetic biomaterials are tested; however, only a minimum of clinical results have been published so far $(2,11,16)$. On the basis of recent work, it is necessary to perform further studies to verify the application of synthetic biomaterials during revision hip operations. Thus, clinical study is being prepared by us to assess synthetic tricalcium phosphate, which serves as a carrier for bone marrow cells, that will be applied to femoral bone defects during revision surgery for total hip replacements.

\section{Conclusion}

This study found an excellent osteointegration of the Lima uncemented tapered fluted revision modular stem in a defective femur with a cortical bone segment present in the area of the femoral isthmus of the diaphysis, allowing vertically and rotationally stable distal fixation. Despite firm intraoperative anchorage of the endoprosthesis' distal module, with a very short femoral isthmus, its subsidence cannot be ruled out. The minimal initial vertical instability, which led to stem migration during the first six weeks following surgery did not, however, affect its osteointegration.

\section{Acknowledgements}

This work was supported by grant IGA MZ CR NT 13477-4. Dr. Diaz-Garcia was supported by the Czech Republic State Budget's project no. CZ.1.07/2.3.00/30.0022.

\section{Conflict of interest}

The authors declare that they have no conflict of interest.

\section{References}

1. Aspenberg P, Wagner P, Nilsson KG, Ranstam J. Fixed or loose? Dichotomy in RSA data for cemented cups. Acta Orthop 2008; 79: 467-73.

2. Beswick A, Blom AW. Bone graft substitutes in hip revision surgery: a comprehensive overview. Injury 2011; 42: S40-6.

3. Blackley HR, Davis AM, Hutchison CR, Gross AE. Proximal femoral allografts for reconstruction of bone stock in revision arthroplasty of the hip. A nine to fifteen-year follow-up. J Bone Joint Surg Am 2001; 83-A: 346-54.

4. Bohm P, Bischel O. Femoral revision with the Wagner SL revision stem: evaluation of one hundred and twenty-nine revisions followed for a mean of 4.8 years. J Bone Joint Surg Am 2001; 83-A: 1023-31.

5. Bozic KJ, Kurtz SM, Lau E, Ong K, Vail TP, Berry DJ. The epidemiology of revision total hip arthroplasty in the United States. J Bone Joint Surg Am 2009; 91-A: 128-33. 
6. Brooker AE, Bowerman JW, Robinson RA, Riley LH. Ectopic ossification following total hip replacement. Incidence and a method of classification. J Bone Joint Surg Am 1973; 55-A: 1629-32.

7. Charnley J. The long-term results of low-friction arthroplasty of the hip performed as a primary intervention. J Bone Joint Surg Br 1972; 54-B: 61-76.

8. Della Valle CJ, Paprosky WG. The femur in revision total hip arthroplasty evaluation and classification. Clin Orthop Relat Res 2004; 420: 55-62.

9. Dohmae Y, Bechtold JE, Sherman RE, Puno RM, Gustilo RB. Reduction in cement-bone interface shear strength between primary and revision arthroplasty. Clin Orthop Relat Res 1988; 236: 214-20

10. Fetzer GB, Callaghan JJ, Templeton JE, Goetz DD, Sullivan PM, Johnston RC. Impaction allografting with cement for extensive femoral bone loss in revision hip surgery: a 4 - to 8 -year follow-up study. J Arthroplasty 2001; 16 : 195-202.

11. Fujishiro T, Nishikawa T, Niikura T, Takikawa S, Saegusa Y, Kurosaka M, Bauer TW. Histologic analysis of allograft mixed with hydroxyapatite-tricalcium phosphate used in revision femoral impaction bone grafting. Orthopedics 2008; 31: 277.

12. Gie GA, Linder L, Ling RS, Simon JP, Slooff TJ, Timperley AJ. Impacted cancellous allografts and cement for revision total hip arthroplasty. J Bone Joint Surg Br 1993; 75-B: 14-21.

13. Gruen TA, McNeice GM, Amstutz HC. "Modes of failure" of cemented stem-type femoral components: a radiographic analysis of loosening. Clin Orthop Relat Res 1979; 141: 17-27.

14. Hartman CW, Garvin KL. Femoral fixation in revision total hip arthroplasty. J Bone Joint Surg Am 2011; 93-A: 2311-22.

15. Head WC, Wagner RA, Emerson RH Jr, Malinin TI. Revision total hip arthroplasty in the deficient femur with a proximal load-bearing prosthesis. Clin Orthop Rela Res 1994; 298: 119-26.

16. Hoshino M, Namikawa T, Kato M, Terai H, Taguchi S, Takaoka K. Repair of bone defects in revision hip arthroplasty by implantation of a new bone-inducing material comprised of recombinant human BMP-2, Beta-TCP powder, and a biodegradable polymer: an experimental study in dogs. J Orthop Res 2007 ; 25: $1042-51$.

17. Karrholm J, Hultmark P, Carlsson L, Malchau H. Subsidence of a nonpolished stem in revisions of the hip using impaction allograft. Evaluation with radiostereometry and dual-energy x-ray absorptiometry. J Bone Joint Surg Br 1999; 81-B: $135-42$.
18. Kroell A, Beaule P, Krismer M, Behensky H, Stoeckl B, Biedermann R. Aseptic stem loosening in primary THA: migration analysis of cemented and cementless fixation. Int Orthop 2009; 33: 1501-5.

19. Kurtz S, Ong K, Lau E, Mowat F, Halpern M. Projections of primary and revision hip and knee arthroplasty in the United States from 2005 to 2030. J Bone Joint Surg Am 2007; 89-A: 780-5.

20. Landor I, Vavř́k P, Gallo J, Sosna A. Revision operations of total hip replacements. Praha: Maxdorf, 2012.

21. Malkani AL, Settecerri JJ, Sim FH, Chao EY, Wallrichs SL. Long-term results of proximal femoral replacement for non-neoplastic disorders. J Bone Joint Surg Br 1995; 77-B: 351-56.

22. Mayle RE, Paprosky WG. Masive bone loss. Allograft-prosthetic composites and beyond. J Bone Joint Surg Br 2012; 94-B: 61-64.

23. McInnis DP, Horne G, Devane PA. Femoral revision with a fluted, tapered, modular stem seventy patients followed for a mean of 3.9 years. J Arthroplasty 2006 21: $372-80$.

24. Mjoberg B. Fixation and loosening of hip prostheses. A review. Acta Orthop Scand 1991; 62: 500-8

25. Noble PC, Alexander JW, Lindahl LJ, Yew DT, Granberry WM, Tullos HS. The anatomic basis of femoral design. Clin Orthop Relat Res 1988; 235: 148-65.

26. Park YS, Moon YW, Lim SJ. Revision total hip arthroplasty using a fluted and tapered modular distal fixation stem with and without extended trochanteric osteotomy. J Arthroplasty 2007; 22: 993-9.

27. Pekkarinen J, Alho A, Lepisto J, Ylikoski M, Ylinen P, Paavilainen T. Impaction bone grafting in revision hip surgery. A high incidence of complications. J Bone Joint Surg Br 2000; 82-B: 103-7.

28. Rodriguez JA, Fada R, Murphy SB, Rasquinha VJ, Ranawat CS.Two-year to five-year follow-up of femoral defects in femoral revision treated with the link MP modular stem. J Arthroplasty 2009; 24: 751-58.

29. Špička J, Radová L, Gallo J. Cementless Plasmacup-Bicontact total hip arthroplasty. Results of a minimum of ten-year follow-up, Acta Chir Orthop Traumatol Cech 2012; 79: 317-23

30. van Biezen FC, ten Have BL, Verhaar JA. Impaction bone-grafting of severely defective femora in revision total hip surgery: 21 hips followed for 41-85 months. Acta Orthop Scand 2000; 71: 135-42.

31. Weiss RJ, Beckman MO, Enocson A, Schmalholz A, Stark A. Minimum 5-year follow-up of a cementless, modular, tapered stem in hip revision arthroplasty. J Arthroplasty 2011; 26: 16-23.

\section{Corresponding author:}

Assoc. Prof. Pavel Šponer, M.D., Ph.D., Department of Orthopaedic Surgery, University Hospital, Sokolská 581, 50005 Hradec Králové, Czech Republic; e-mail: sponer.p@seznam.cz 